\title{
Development of Electrohydraulic Steering Control System for Tractor Automatic Navigation
}

\author{
Chengqiang Yin $\left(\mathbb{D},{ }^{1}\right.$ Qun Sun $\left(\mathbb{D},{ }^{1}\right.$ Jian Wu, ${ }^{1}$ Chengqiang Liu, ${ }^{2}$ and Jie Gao ${ }^{1}$ \\ ${ }^{1}$ School of Mechanical and Automobile Engineering, Liaocheng University, Liaocheng 252059, China \\ ${ }^{2}$ Shifeng Group Co., Ltd., Liaocheng 252800, China \\ Correspondence should be addressed to Chengqiang Yin; shtjycq@163.com
}

Received 22 July 2017; Accepted 12 December 2017; Published 1 February 2018

Academic Editor: Jit S. Mandeep

Copyright (c) 2018 Chengqiang Yin et al. This is an open access article distributed under the Creative Commons Attribution License, which permits unrestricted use, distribution, and reproduction in any medium, provided the original work is properly cited.

\begin{abstract}
The most of tractors employed in agriculture are equipped with an electrohydraulic actuator to implement steering control to realize automatic navigation. Electrohydraulic steering system plays an important role in realizing accurate steering control for an automatic navigation tractor because of its complicated characteristics. The objective of this paper is to develop an electrohydraulic steering control system used for automatically guided agricultural tractors. As for the identified electrohydraulic steering system model, a modified Smith control structure was discussed. Based on the structure, an improved design method for voltage servo controller and disturbance rejection controller was proposed to enhance the performance of the steering control subsystem. The effectiveness and the superiority of the proposed method were verified by simulation under Matlab. Simulation results demonstrated the efficiency of the proposed method by showing fast response, control accuracy, and robust performance for the steering control system.
\end{abstract}

\section{Introduction}

Agricultural modernization has been realized in most field operations such as tillage, harvesting, weeding, land preparation [1]. Automatic navigation technology of agricultural machinery is one of the most important support technologies for modern agricultural equipment. Its application in precision agriculture is regarded as one of the main issues noteworthy for efficiency improvement [2-6] and lower cost [7]. It would desirable to offer the promise of higher efficiency, better and more consistent performance, and reduced labor costs and release the operator from driving to concentrate on implementing other functions. The need for tractor has been reinforced because of its advance in application technology [8].

Automatic steering is the execution of the steering commands which were generated by other intelligent units in order to follow an optimal trajectory. A qualified automatic steering system requires high control accuracy, good reliability, and fast response [9-12]. Electrohydraulic steering is used for the most automatic steering tractors, and it is becoming common practice to provide large forces to actuate steering mechanism by a hydraulic cylinder governed by a directional valve. The control accuracy of an electrohydraulic steering system determines the control accuracy of the automatic navigation system $[13,14]$. In order to achieve accurate and prompt steering control on an automated agricultural tractor with an electrohydraulic steering system, Wu et al. [15] designed an adaptive controller which consisted of an adaptive gain tuner and an adaptive nonlinearity compensator. Luo et al. [16] designed a hydraulic steering system connected in parallel with the original mechanical steering system. $\mathrm{Li}$ et al. [17] designed an automatic steering controller and proposed a double closed-loop control algorithm to realize autonomous navigation of agricultural machinery. Fu et al. [18] proposed the method for supporting agricultural priority drivers manually operated steering and designed the electrohydraulic automatic steering scheme. Wu et al. [19] developed a hydrostatic transmission hardware-in-the-loop simulator for supporting vehicle transmission system research; they used linear parameter-varying approach to model the simulator and used swept-sine technique for identifying the models in the frequency domain. Similarly, Rovira-Más et al. [20] investigated the dynamics of an electrohydraulic steering 


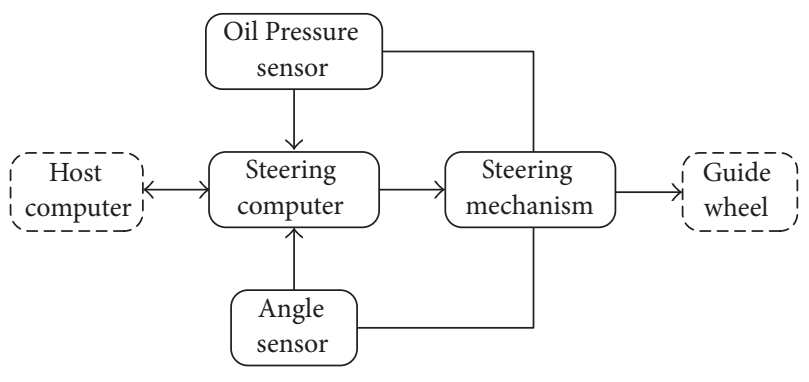

FIGURE 1: Automatic steering system structure.

system and characterized the performance of an electrohydraulic valve with the aid of a set of experiments conducted on a hardware-in-the-loop electrohydraulic simulator. In the design and evaluation of a force controller for an electrohydraulic actuator, Niksefat and Sepehri [21] developed two approaches to identify linear time-invariant equivalent model and employed nonlinear version of quantitative feedback theory to design a robust time-invariant controller. RoviraMás and Zhang [22] designed an electrohydraulic steering control system for agricultural vehicles and developed a fuzzy steering controller with this electrohydraulic steering control system. Zhang [23] designed a generic fuzzy steering controller for an agricultural tractor with a hydraulic steering actuator and an electrohydraulic steering control valve, and the controller was tested on a hardware-in-loop electrohydraulic steering simulator and on two agricultural tractors.

In this paper, we seek to design an electrohydraulic steering control system for autonomously guided agriculture tractors. A control method is proposed in order to improve the steering performance. The paper is organized as follows. The automatic steering control system is designed in Section 2. The mathematical model of the electrohydraulic steering used on the tractor navigation platform is proposed in Section 3. The form of the steering controller and design specifications are given in Section 4. Simulations are carried out to demonstrate the validity of the proposed control program in Section 5.

\section{Steering System Design}

2.1. Automatic Steering System Structure. In order to realize steering either manually or automatically, a direction proportional electrohydraulic valve is installed in parallel with the existing hand pump. The automatic steering system consists of steering control section and steering mechanism section. The system structure is shown in Figure 1. The control commands from the host computer are sent to the steering computer via RS-232 bus communication unit. The wheel turning angle is measured by the angle sensor in real time. The commands of desired steering angle from the host computer and the signal of wheel turning angle are received and processed by the steering computer; then a controlling continuous voltage raging from $-10 \mathrm{~V}$ to $+10 \mathrm{~V}$ is sent to the steering mechanism to adjust the proportional electrohydraulic valve to control the guide wheel. The signal of oil pressure is used to confirm the steering status. The

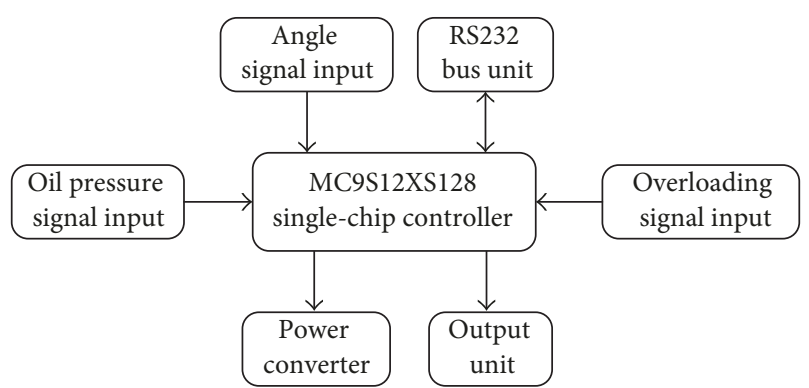

Figure 2: Automatic steering control system structure.

steering computer will switch to the manual steering model if the signal for the pressure sensor is a high-level signal or a pulse signal.

2.2. Automatic Steering Control System Design. Automatic steering control system consists of a Freescale MC9S12XS128 single-chip controller, RS23 bus unit, power convert unit, output unit, overload signal input unit, angle signal input unit, and pressure signal input unit. The control system structure is shown in Figure 2.

Because the tractor can only provide voltage $12 \mathrm{~V} \mathrm{DC}$, voltage stabilization module SDW50-12S24 is selected to convert $12 \mathrm{~V}$ DC into $24 \mathrm{~V}$ DC, and voltage stabilization module SDW50-12S5 is selected to convert $12 \mathrm{~V}$ DC into $5 \mathrm{~V} \mathrm{DC}$. As for the output unit, the control signal from the controller is demanded between $-10 \mathrm{~V}$ and $+10 \mathrm{~V}$, DAC0832 chip is selected to output continuous voltage from $-10 \mathrm{~V}$ to $+10 \mathrm{~V}$, and at the same time WD12-5D15B1 unit is selected to provide standard external voltage between $-15 \mathrm{~V}$ and $+15 \mathrm{~V}$ for amplifier, choosing AD581 unit to provide $10 \mathrm{~V}$ reference voltage for DAC0832 chip. As for the overload signal input unit, ISO-A4-P1-O4 module is selected to transfer the input of 4-20 mA standard signal into $5 \mathrm{~V}$ isolated signal for ensuring safety for the hydraulic valve [2]. As for the angle signal input unit, we select a linear potentiometer attached on the hydraulic steering cylinder as an angle sensor.

\section{Modeling of Steering System}

As a control system, the output of the steering system can be regarded the angular position of front wheels corresponding to the steering control input voltage $u$. The steering system can be modeled as

$$
G(s)=\frac{\Phi(s)}{U(s)}=\frac{K}{s(T s+1)\left(s^{2}+2 \xi \omega_{n} s+\omega_{n}^{2}\right)} .
$$

Generally, the natural frequency of the valve, $\omega_{n}$, is much higher than that of the steering system. Therefore, steering control system could be further simplified as a second order model. With the consideration of friction and steering loads, a system time delay term could be added in order to improve the model accuracy [24]. So with the control voltage signal $U(s)$ as the control input and the guide wheel angular position $\Phi(s)$ as the control output, the open-loop transfer function of 


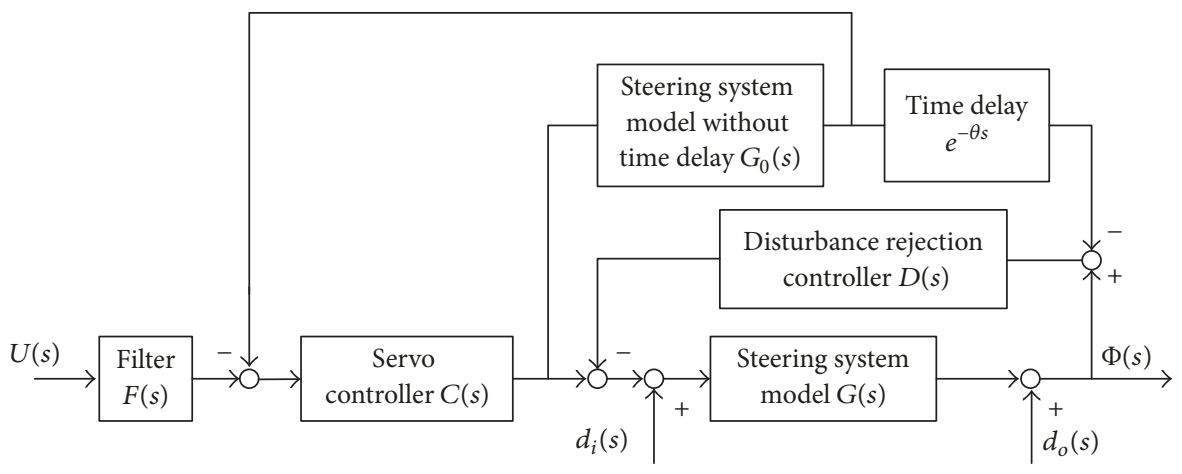

FIgURe 3: Modified Smith control structure.

the electrohydraulic steering system model can be simplified as

$$
G(s)=\frac{\Phi(s)}{U(s)}=\frac{K}{s(T s+1)} e^{-\theta s} .
$$

\section{Control Scheme Design}

Steering controller for tractor automatic navigation should provide an appropriate steering response and account for variations in operating state according to the unprepared and unpredictable terrain. It is invalid for the conventional control technology because of the complicated character of the electrohydraulic steering system combined with the unpredictable field conditions. A two-degree-of-freedom control scheme based on modified Smith predictor is proposed, and it can improve the disturbance rejection performance as well as servo tracking performance. The proposed control structure is shown in Figure 3. Where $G(s)$ is the steering system, and $G_{0}(s)$ is the steering system model without the time delay, that is, $G(s)=G_{0}(s) e^{-\theta s}$. $C(s)$ is the servo controller, and it is used for the purpose of reducing the deviation and realizing the tracking to the value of the voltage. $D(s)$ is the disturbance rejection controller, and it is used for rejecting the disturbance before or after process. $F(s)$ is the servo filter. $U(s)$ is the control voltage, and $\Phi(s)$ is the guide wheel angular. $d_{i}(s)$ and $d_{o}(s)$ are the disturbances before and after process, respectively.

4.1. Servo Controller Design. Assuming the model exactly represents the process, that is, $G(s)=G_{0}(s) e^{-\theta s}$, the closedloop transfer function can be determined in the form of

$$
H_{r}(s)=\frac{\Phi(s)}{U(s)}=\frac{G(s) C(s)}{1+G_{0}(s) C(s)} .
$$

It can be observed from (3) that the characteristic equation does not contain any time delay. So direct synthesis method is used to design the controller.

$$
C(s)=\frac{1}{G_{0}(s)} \frac{H_{r d}(s)}{1-H_{r d}(s)},
$$

where $H_{r d}(s)$ is the desired closed-loop trajectory for set point changes. Considering the implementation and system performance, the desired set point tracking transfer function is proposed

$$
H_{r d}(s)=\frac{a_{2} s^{2}+a_{1} s+1}{(\lambda s+1)^{3}},
$$

where $\lambda$ is the adjustable parameter. We can get the controller from (4) and (5).

$$
C(s)=\frac{(T s+1)\left(a_{2} s^{2}+a_{1} s+1\right)}{k\left[\lambda^{3} s^{2}+\left(3 \lambda^{2}-a_{2}\right) s+\left(3 \lambda-a_{1}\right)\right]},
$$

where $a_{1}=3 \lambda$ and $a_{2}=3 \lambda^{2}-\lambda^{3} / T$. To obtain a realizable controller, $C(s)$ can be realized in discrete form or approximated by a rational transfer function. Here we expand (6) a PID controller in form of

$$
C(s)=k_{1}\left(1+\frac{1}{\tau_{i 1} s}+\tau_{d 1} s\right),
$$

where $k_{1}=3 T / k \lambda^{2}$ is proportional gain, $\tau_{i 1}=3 \lambda$ is integral gain, and $\tau_{d 1}=\lambda(1-\lambda / 3 T)$ is derivative gain. When $\lambda$ is tuned to be small, the servo performance becomes faster but the output energy of the controller $C(s)$ becomes larger and vice versa. The primary requirement for selection of $\lambda$ is that the resulting controller gains should be positive for positive values of process model gain. Based on many simulation studies, it is observed that the starting values of the tuning parameter $\lambda_{c 1}$ can be taken as $0.3 \theta$. If good control performances are not achieved with this value, then the tuning parameter can be increased gradually from this value. The range of the tuning parameter that gives good control performances is $0.3 \theta-1.5 \theta$.

4.2. Filter Design. As can be seen from (5), this closed-loop transfer function zero introduces an overshoot for the servo response for the electrohydraulic process. Also, whenever there are step changes in the set point, there is possibility that there exists set point kick. So in order to improve the servo performance and reduce the overshoot, a set point filer is designed

$$
F(s)=\frac{1}{a_{2} s^{2}+a_{1} s+1} .
$$


But because the controller $C(s)$ is obtained using the approximate method, the filter can be adjusted near $a_{2}$ and $a_{1}$ in practice to obtain the excellent servo performance.

4.3. Disturbance Rejection Controller Design. In order to design the disturbance rejection controller, we transform the open-loop transfer function $G(s)$ to $G(s)=-K^{\prime} e^{-\theta s} /\left[\left(T^{\prime} s-\right.\right.$ $1)(-T s-1)]$. In the proposed control structure shown in Figure 3, we can obtain the closed-loop complementary sensitivity function between the process input and output for the load disturbance rejection as

$$
T(s)=\frac{D(s) G(s)}{1+D(s) G(s)} .
$$

Here, $D(s)$ is designed using the method of unit feedback based on internal mode control theory [25].

$$
\frac{D(s) G(s)}{1+D(s) G(s)}=G(s) C_{i}(s),
$$

where $C_{i}(s)$ is the internal mode controller, $G(s)=$ $G_{-}(s) G_{+}(s), C_{i}(s)=G_{-}^{-1}(s) f(s)$, in which $f(s)$ is the filter, $G_{-}(s)=-K^{\prime} /\left[\left(T^{\prime} s-1\right)(-T s-1)\right]$, and $G_{+}(s)=e^{-\theta s}$. In order to ensure that the system is internally stable, the filter is designed as

$$
f(s)=\frac{b_{2} s^{2}+b_{1} s+1}{\left(\lambda^{\prime} s+1\right)^{4}} .
$$

Subsequently, we get the internal mode controller

$$
C_{i}(s)=\frac{\left(T^{\prime} s-1\right)(-T s-1)}{-K^{\prime}} \frac{b_{2} s^{2}+b_{1} s+1}{\left(\lambda^{\prime} s+1\right)^{4}} .
$$

Then substituting (12) into (10) obtains the controller $D(s)$

$$
D(s)=\frac{\left(T^{\prime} s-1\right)(T s+1)\left(b_{2} s^{2}+b_{1} s+1\right)}{k^{\prime}\left[\left(\lambda^{\prime} s+1\right)^{4}-e^{-\theta s}\left(b_{2} s^{2}+b_{1} s+1\right)\right]},
$$

where $\lambda^{\prime}$ is an adjustable parameter which realizes the tradeoff between the performance and robustness and $b_{1}$ and $b_{2}$ are determined by the two constraints

$$
\begin{aligned}
& \lim _{s \rightarrow 1 / T}\left[1-\frac{b_{2} s^{2}+b_{1} s+1}{\left(\lambda^{\prime} s+1\right)^{4}} e^{-\theta s}\right]=0, \\
& \lim _{s \rightarrow 1 / T^{\prime}}\left[1-\frac{b_{2} s^{2}+b_{1} s+1}{\left(\lambda^{\prime} s+1\right)^{4}} e^{-\theta s}\right]=0 .
\end{aligned}
$$

The dead time $e^{-\theta s}$ in (13) is approximated using Pade expansion $e^{-\theta s}=(1-\theta s / 2) /(1+\theta s / 2)$. Since the resulting controller does not have a standard PID controller form, a procedure is employed to produce a PID controller cascade with a first-order lead-lag filter.

$$
D(s)=k_{2}\left(1+\frac{1}{\tau_{i 2} s}+\tau_{d 2} s\right) \frac{1+\alpha^{\prime} s}{1+\beta s},
$$

where $k_{2}=b_{1} / k^{\prime}\left(4 \lambda^{\prime}+\theta-b_{1}\right)$ is proportional gain, $\tau_{i 2}=b_{1}$ is integral gain, and $\tau_{d 2}=b_{2} / b_{1}$ is derivative gain. $\alpha^{\prime}=$ $0.5 \theta$ and $\beta=\left(b_{1} \theta / 2-b_{2}+2 \lambda^{\prime} \theta+6 \lambda^{\prime 2}\right) /\left(\theta+4 \lambda^{\prime}-b_{1}\right)+$ $T+T^{\prime}$, and they are parameters of the lead-lag filter. It can be seen form (3) and (10) that the response of set point tracking and the load disturbance rejection are decoupled completely; we can adjust the performance of disturbance rejection using the adjustable parameter $\lambda^{\prime}$. Decreasing $\lambda^{\prime}$ improves the disturbance rejection performance but decays its robust stability; on the contrary, increasing $\lambda^{\prime}$ tends to strengthen the robust stability of the closed-loop but degrades its disturbance rejection performance. The starting values of the $\lambda^{\prime}$ can be set equal to the process time delay.

\section{Simulation Results}

According to the experimental results obtained on the electrohydraulic steering system, we get the model parameters of the open-loop transfer functions $K=22.7, T=0.05$, and $\theta=0.12$. In the proposed method, take $\lambda=0.06$, by employing the design formulate (5), (7), and obtain the servo controller in form of

$$
C(s)=1.8355\left(1+\frac{1}{0.18 s}+0.036 s\right) .
$$

By employing the design formulate (8) and obtain the filter $F(s)=1 /\left(0.0065 s^{2}+0.18 s+1\right)$. In the same way, take $T^{\prime}=100, \lambda^{\prime}=0.12$, by employing the design formulate (13), (14), and (15), and obtain the disturbance rejection controller in form of

$$
D(s)=0.217\left(1+\frac{1}{0.6124 s}+0.0473 s\right) \frac{1+0.06 s}{1+0.0606 s} .
$$

Using the identified electrohydraulic steering model, the simulation is programmed using the Matlab Simulink toolbox. For illustration, two groups of simulation test are made for the electrohydraulic steering system with these controllers' settings.

Firstly, by adding a unit step change to the set point input at $t=0 \mathrm{~s}$, an inverse step change of load disturbance with magnitude of 0.05 to the electrohydraulic steering process output at $t=13 \mathrm{~s}$ and an inverse step change of load disturbance with magnitude of 0.2 to the process input at $t=$ $6 \mathrm{~s}$, the simulation results are obtained as shown in Figure 4. Where the solid line denotes the nominal system response, the dot line denotes the unit step signal.

To illustrate the robust stability of the system to the parameters changed in the process $G(s)$, uncertainty of $-20 \%$ in $K, \theta$ and $20 \%$ in $K, \theta$, respectively, is considered. The corresponding response is plotted and shown in Figure 5. Where the solid line denotes the perturbed system response of which $G(s)=18.16 e^{-0.096 s} /\left(0.05 s^{2}+s\right)$, the dot line denotes the perturbed system response of which $G(s)=$ $27.24 e^{-0.144 s} /\left(0.05 s^{2}+s\right)$.

Secondly, a sine wave input is used to further evaluate the controller performance. By giving a unit sinusoidal input in the set point at $t=0 \mathrm{~s}$, a negative disturbance of magnitude 0.05 to the process input at $t=6 \mathrm{~s}$, and a negative 


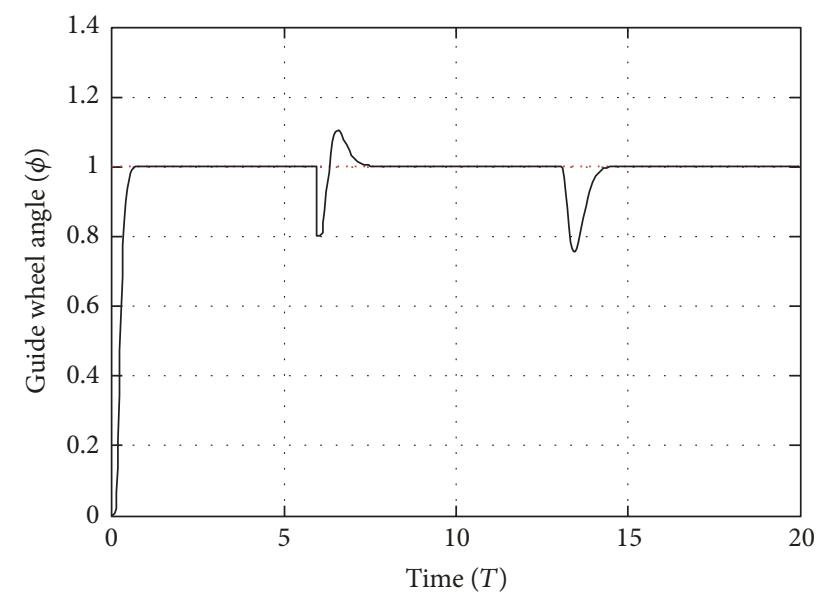

FIGURE 4: Response for perfect model to unit step signal. Solid: system response; dot: unit step signal.

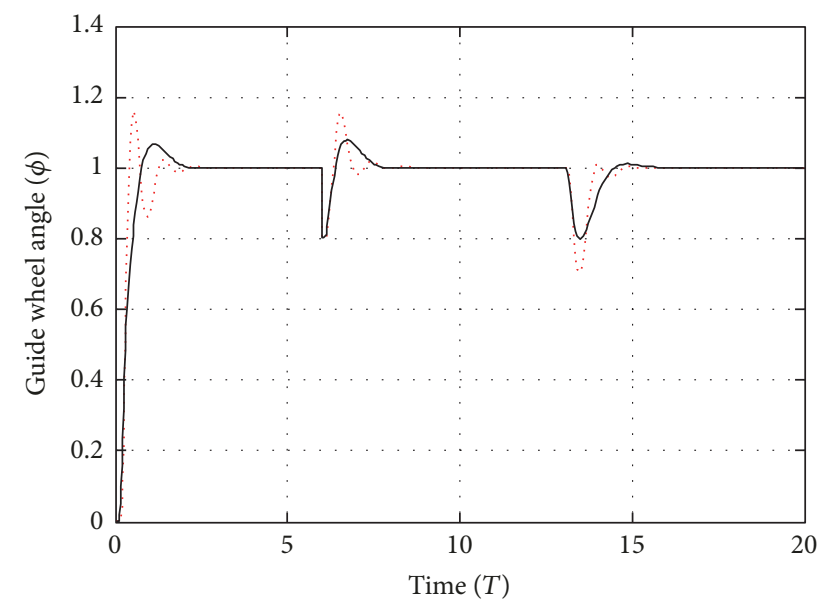

FIgURE 5: Perturbed system responses to unit step signal. Solid: response for perturbations of $-20 \%$ in $K$ and $\theta$; dot: response for perturbations of $20 \%$ in $K$ and $\theta$.

disturbance of magnitude 0.2 to the process output $t=13 \mathrm{~s}$, the corresponding system response is shown in Figure 6.

Where the dot line denotes the sinusoidal signal, the solid line denotes the nominal system response to the sinusoidal input. Similarly, to show the performance of robust stability of the system, now suppose that there exist $20 \%$ errors for estimating the gain $K$ and process time delay $\theta$ such that both of them are actually $20 \%$ larger. The perturbed system response is denoted using the dot line in Figure 7. Supposing the gain $K$ and process time delay $\theta$ are actually $20 \%$ smaller, the perturbed system response is denoted using the solid line in Figure 7.

It can be seen from (2) that the electrohydraulic steering system is an integrating plant. The presence of integrating factor leads to an excessive overshoot and long settling time in some cases and gives rise to consequence that the balance between the input and output may be easily destroyed by a load disturbance. As for this system, the performance and robustness of the controllers designed based on conventional PID methods with unity feedback control structure cannot be

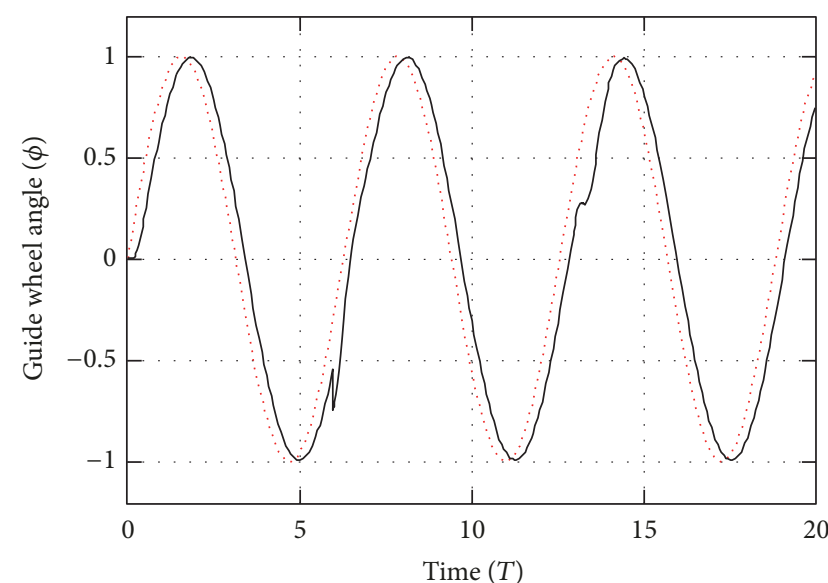

FIGURE 6: Response for perfect model to sinusoidal signal. Solid: system response; dot: sinusoidal signal.

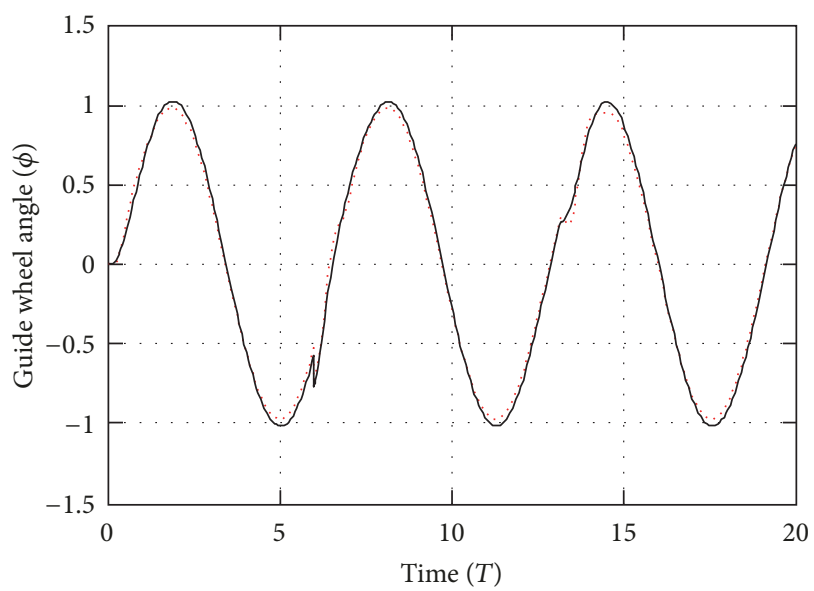

FIGURE 7: Perturbed system responses to sinusoidal signal. Solid: response for perturbations of $-20 \%$ in $K$ and $\theta$; dot: response for perturbations of $20 \%$ in $K$ and $\theta$.

fully achieved. The main advantage of the proposed method is that it is simple with two controllers. It can be seen from the design procedure that the performance of servo and load disturbance rejection response are decoupled completely and can be monotonically tuned to meet a good performance by controllers $C(s)$ and $D(s)$, respectively. What is more, the two controllers are designed with PID form, and the performances can be obtained by the tuning parameters $\lambda$ and $\lambda^{\prime}$, respectively. From the responses illustrated in Figures 4 and 6 , it can be observed that the proposed method for electrohydraulic steering system provides better performance for both set point tracking and disturbance rejection. Figures 5 and 7 show that the designed control system holds the robust stability of the load disturbance response well in the presence of the severe process uncertainty.

\section{Conclusions}

The objective of this investigation is the development of electrohydraulic steering control system for autonomously 
guided agriculture tractor. Firstly, a steering control system has been developed based on single-chip computer, which controlled bipolar electrohydraulic steering valve by controlling continuous output voltage from $-10 \mathrm{~V}$ to $+10 \mathrm{~V}$ according to electronic commands sent from the host computer and real time data obtained from sensors. Secondly, as for the openloop transfer function of the electrohydraulic steering system model with the control voltage signal as the control input and the guide wheel angular position as the control output, a modified Smith predictor scheme was proposed based on a two-degree-of-freedom control structure. Servo controller and disturbance rejection controller were all designed in the form of PID and could be monotonically tuned by a single adjustable parameter, respectively. Lastly, simulation results demonstrated the validity of the proposed control scheme.

\section{Conflicts of Interest}

The authors declare that there are no conflicts of interest regarding the publication of this paper.

\section{Acknowledgments}

This project is funded by Shandong Province Key Technologies R\&D Program (no. 2016GNC112014), the science and technology funds of Shandong Education Department (no. J15LB09), and the Scientific Research Fund of Liaocheng University, China (no. 318011519).

\section{References}

[1] M. Z. Song, S. W. Kang, and S. O. Chung, "Development of Path Planning Algorithm for an Autonomous Mower Tractor," in Proceedings of the IFAC Conference on Modelling and Control in Agriculture, Horticulture and Post Harvest Industry, vol. 4, pp. 154-158, 2013.

[2] Q. Sun, S. M. Teng, and Y. Q. Du, "Research on Calibration Method for Tractor Automatic Navigation Control System," The Open Electrical \& Electronic Engineering Journal, vol. 10, no. 1, pp. 129-140, 2016.

[3] J. T. Hu, L. Gao, and X. P. Bai, "Review of research on automatic guidance of agricultural vehicles," Transactions of the Chinese Society of Agricultural Engineering, vol. 31, no. 10, pp. 1-10, 2015.

[4] R. Eaton, J. Katupitiya, K. W. Siew, and B. Howarth, "Autonomous farming: modelling and control of agricultural machinery in a unified framework," International Journal of Intelligent Systems Technologies and Applications, vol. 8, no. 1-4, pp. 444-457, 2010.

[5] H. Mousazadeh, "A technical review on navigation systems of agricultural autonomous off-road vehicles," Journal of Terramechanics, vol. 50, no. 3, pp. 211-232, 2013.

[6] J. V. Stafford, "Implementing precision agriculture in the 21st century," Journal of Agricultural Engineering Research, vol. 76, no. 3, pp. 267-275, 2000.

[7] A. J. Lipiński, P. Markowski, S. Lipiński, and P. Pyra, "Precision of tractor operations with soil cultivation implements using manual and automatic steering modes," Biosystems Engineering, vol. 145, pp. 22-28, 2016.

[8] Q. Zhang, D. Wu, J. F. Reid, and E. R. Benson, "Model recognition and validation for an off-road vehicle electrohydraulic steering controller," Mechatronics, vol. 12, no. 6, pp. 845-858, 2002.

[9] J.-Y. Liu, J.-Q. Tan, E.-R. Mao, Z.-H. Song, and Z.-X. Zhu, "Proportional directional valve based automatic steering system for tractors," Frontiers of Information Technology and Electronic Engineering, vol. 17, no. 5, pp. 458-464, 2016.

[10] Z. Dong, Q. Zhang, and S. Han, "Control an electrohydraulic steering system using a PID controller with a nonlinear compensation algorithm," in Proceedings of the Unmanned Ground Vehicle Technology IV, pp. 87-95, USA, April 2002.

[11] M. Bodur, E. Kiani, and H. Hacişevki, "Double look-ahead reference point control for autonomous agricultural vehicles," Biosystems Engineering, vol. 113, no. 2, pp. 173-186, 2012.

[12] Z.-X. Zhu, J. Chen, T. Yoshida, R. Torisu, Z.-H. Song, and E.-R. Mao, "Path tracking control of autonomous agricultural mobile robots," Journal of Zhejiang University SCIENCE A, vol. 8, no. 10, pp. 1596-1603, 2007.

[13] J. F. Reid, Q. Zhang, N. Noguchi, and M. Dickson, "Agricultural automatic guidance research in North America," Computers and Electronics in Agriculture, vol. 25, no. 1-2, pp. 155-167, 2000.

[14] L. García-Pérez, M. C. García-Alegre, A. Ribeiro, and D. Guinea, "An agent of behaviour architecture for unmanned control of a farming vehicle," Computers and Electronics in Agriculture, vol. 60, no. 1, pp. 39-48, 2008.

[15] D. Wu, Q. Zhang, and J. F. Reid, "Adaptive steering controller using a Kalman estimator for wheel-type agricultural tractors," Robotica, vol. 19, no. 5, pp. 527-533, 2001.

[16] X. W Luo, Z. G, Zhang., and Z. X Zhao, "Design of DGPS navigation control system for Dongfanghong X-804 tractor," Transactions from the Chinese Society of Agricultural Engineering, vol. 25, no. 11, pp. 139-145, 2009, in Chinese.

[17] Y. Li, Z. Zhao, P. Huang, and W. Guan, "Design and experiment of automatic steering control system based on Dongfanghong tractor," Nongye Gongcheng Xuebao, vol. 31, pp. 93-99, 2015.

[18] W. Fu, G. Wu, Y. Cong, Y. Li, and Z. Meng, "Development of tractor automatic steering system with manual priority function," in Proceedings of the 5th Annual IEEE International Conference on Cyber Technology in Automation, Control and Intelligent Systems, IEEE-CYBER 2015, pp. 555-559, China, June 2015.

[19] K. Wu, Q. Zhang, and A. Hansen, "Modelling and identification of a hydrostatic transmission hardware-in-the-loop simulator," International Journal of Vehicle Design, vol. 34, no. 1, pp. 52-64, 2004.

[20] F. Rovira-Más, Q. Zhang, and A. C. Hansen, "Dynamic behavior of an electrohydraulic valve: Typology of characteristic curves," Mechatronics, vol. 17, no. 10, pp. 551-561, 2007.

[21] N. Niksefat and N. Sepehri, "Design and experimental evaluation of a robust force controller for an electro-hydraulic actuator via quantitative feedback theory," Control Engineering Practice, vol. 8, no. 12, pp. 1335-1345, 2000.

[22] F. Rovira-Más and Q. Zhang, "Fuzzy logic control of an electrohydraulic valve for auto-steering off-road vehicles," Proceedings of the Institution of Mechanical Engineers, Part D: Journal of Automobile Engineering, vol. 222, no. 6, pp. 917-934, 2008.

[23] Q. Zhang, "Design of a generic fuzzy controller for electrohydraulic steering," in Proceedings of the 2001 American Control Conference, pp. 3938-3942, Arlington, Va, USA, June 2001.

[24] H. Qiu, Q. Zhang, J. Reid, and D. Wu, "System identification of an electrohydraulic steering system," SAE Technical Papers, 1999. 
[25] M. Shamsuzzoha and M. Lee, "Enhanced performance for twodegree-of-freedom control scheme for second order unstable processes with time delay," in Proceedings of the International Conference on Control, Automation and Systems (ICCAS '07), pp. 240-245, Seoul, Republic of Korea, October 2007. 


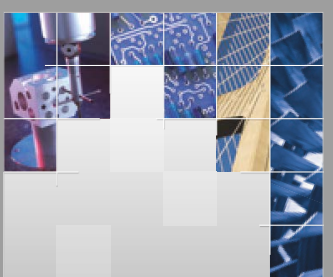

\section{Enfincering}
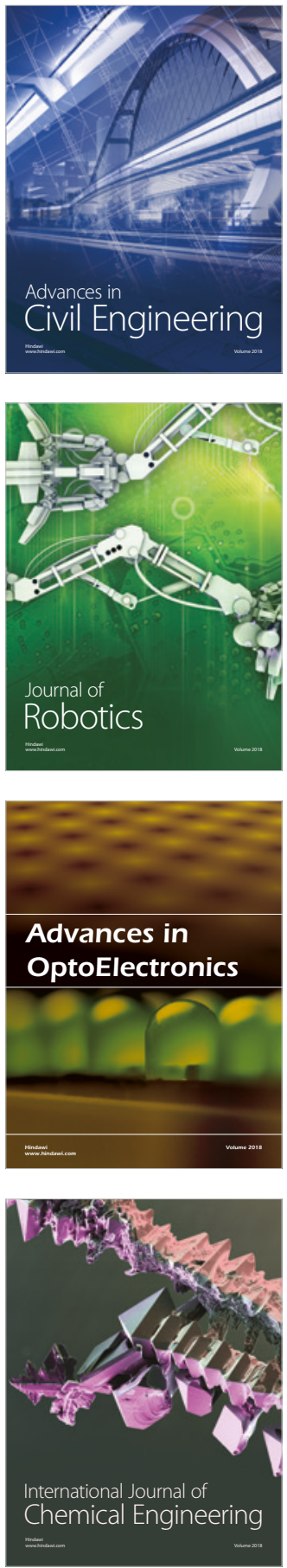

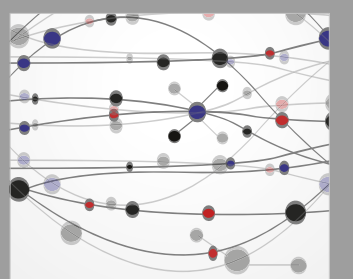

\section{Rotating \\ Machinery}

The Scientific World Journal

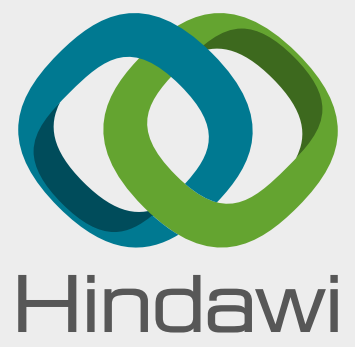

Submit your manuscripts at

www.hindawi.com
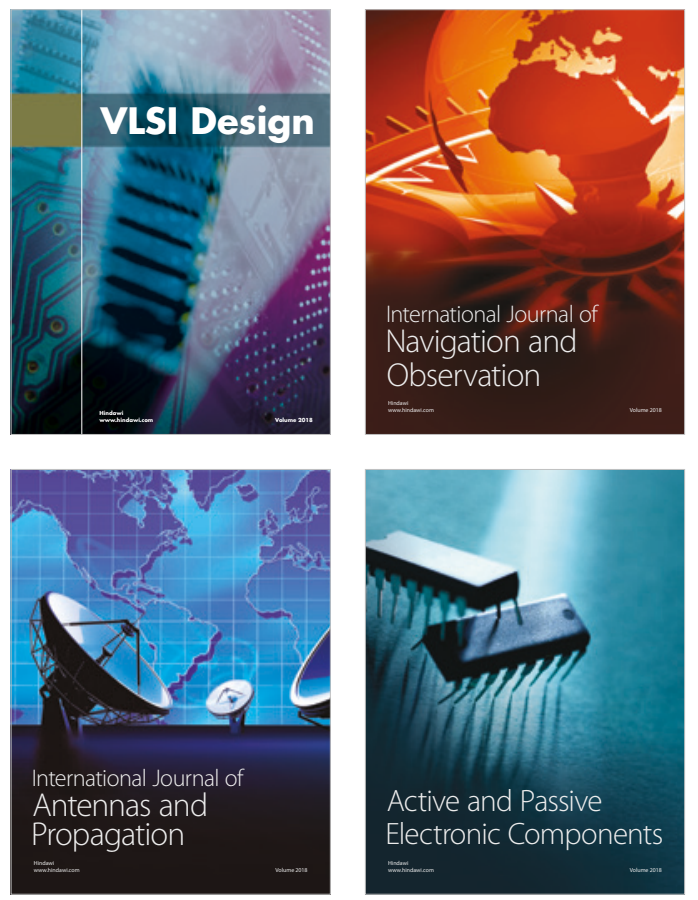
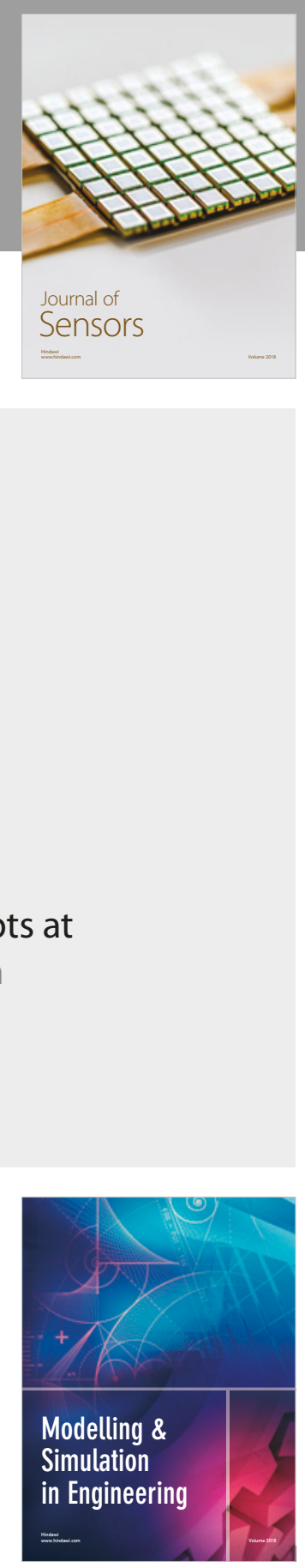

\section{Advances \\ Multimedia}
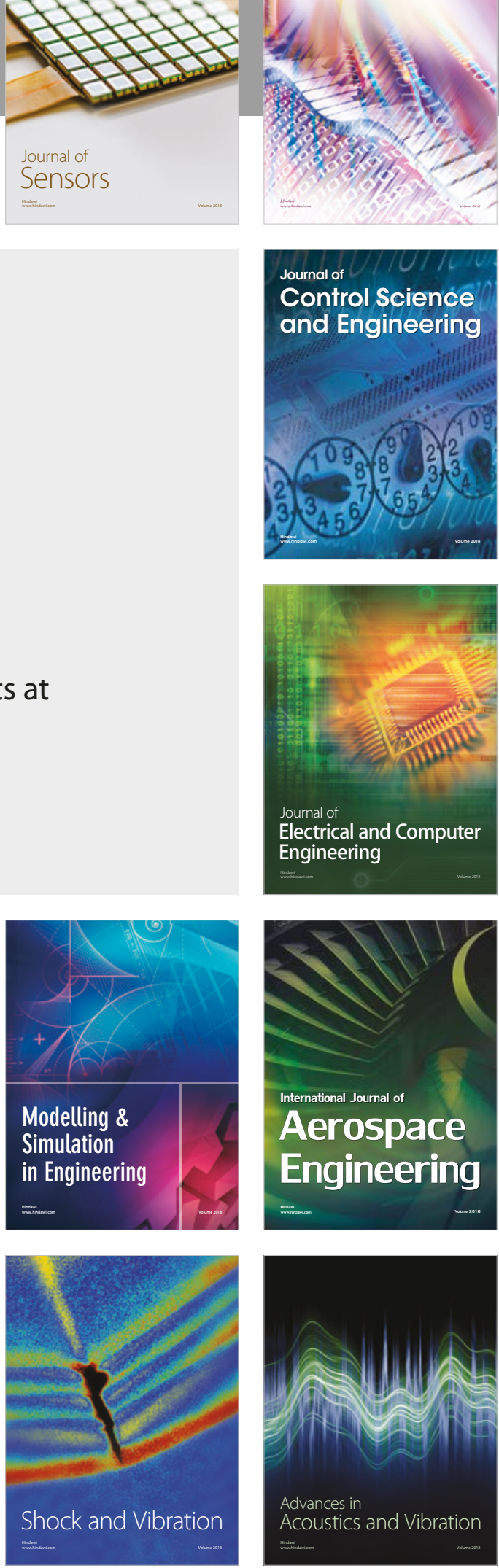